\title{
Issues and Challenges: The Development of Fair and Equitable Health Policy
}

Rachele Hendricks-Sturrup

Nova Southeastern University, rh802@nova.edu

Follow this and additional works at: https://nsuworks.nova.edu/ijahsp

Part of the Health Law and Policy Commons, and the Medicine and Health Sciences Commons

\section{Recommended Citation}

Hendricks-Sturrup R. Issues and Challenges: The Development of Fair and Equitable Health Policy. The Internet Journal of Allied Health Sciences and Practice. 2016 Jan 01;14(4), Article 9.

This Opinion Piece is brought to you for free and open access by the College of Health Care Sciences at NSUWorks. It has been accepted for inclusion in Internet Journal of Allied Health Sciences and Practice by an authorized editor of NSUWorks. For more information, please contact nsuworks@nova.edu. 


\title{
Issues and Challenges: The Development of Fair and Equitable Health Policy
}

\begin{abstract}
Public health policy/law is a discipline that seeks to identify opportunities and implement mechanisms to achieve justice in the public health sector. Several public health policies and programs have been implemented by virtue of the Affordable Care Act (ACA), and these policies and programs seek to decrease America's "paradox of excess and deprivation" and address socioeconomic barriers that exist in the U.S. healthcare system. Private healthcare market interests have accused the ACA of intruding heavily into the professional autonomy of the medical profession, eroding healthcare market competition, and driving up national healthcare spending. Counter-arguments defending the ACA state that the law exposes the limitations to such professional autonomy of the medical profession, primarily because the U.S. healthcare system is currently ridden with excess, waste, and social injustice. This review article outlines the types of policies and laws governing healthcare, unique healthcare issues faced by particularly vulnerable populations, and future challenges and opportunities under the ACA. Lastly, the article provides recommendations to address future challenges and opportunities under the ACA, so as to balance the scales between private market interests and public health equity.
\end{abstract}

\section{Author Bio(s)}

Rachele Hendricks-Sturrup is a biomedical scientist and health policy analyst, and holds a Bachelor of Science in Biology, a Master of Science in Pharmacology and Toxicology, and a Master of Art in Legal Studies. She is currently pursuing a Doctor of Health Science at Nova Southeastern University. Her doctoral study focus involves exploring and describing how various forms of biotechnology can be used within the scope of personalized medicine and value-based care. 


\title{
TIAHSP

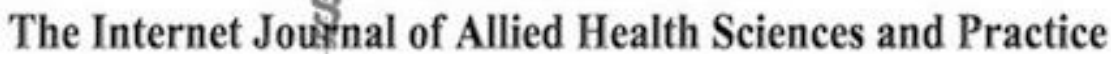

Dedicated to allied health professional practice and education

Vol. 14 No. 4 ISSN 1540-580X

\section{Issues and Challenges: The Development of Fair and Equitable Health Policy}

\author{
Rachele Hendricks-Sturrup \\ Nova Southeastern University \\ United States
}

\begin{abstract}
Public health policy/law is a discipline that seeks to identify opportunities and implement mechanisms to achieve justice in the public health sector. Several public health policies and programs have been implemented by virtue of the Affordable Care Act (ACA), and these policies and programs seek to decrease America's "paradox of excess and deprivation" and address socioeconomic barriers that exist in the U.S. healthcare system. Private healthcare market interests have accused the ACA of intruding heavily into the professional autonomy of the medical profession, eroding healthcare market competition, and driving up national healthcare spending. Counter-arguments defending the ACA state that the law exposes the limitations to such professional autonomy of the medical profession, primarily because the U.S. healthcare system is currently ridden with excess, waste, and social injustice. This review article outlines the types of policies and laws governing healthcare, unique healthcare issues faced by particularly vulnerable populations, and future challenges and opportunities under the ACA. Lastly, the article provides recommendations to address future challenges and opportunities under the ACA, so as to balance the scales between private market interests and public health equity.
\end{abstract}

\section{Introduction}

Public health policy/law concentrates on understanding and formulating ways to achieve a delicate balance between the business autonomy of the private healthcare market and government regulation of the private healthcare market. ${ }^{1} \mathrm{~A}$ major and current example of a public health policy/law is the Patient Protection and Affordable Care Act (commonly referred to as the "ACA"). The ACA (42 U.S.C. § 18001) was signed into law by President Barack Obama and upheld by the Supreme Court in 20122.2

Private market interests have since challenged the ACA, citing that the law intrudes heavily into the professional autonomy of the medical profession, erodes healthcare market competition, and drives up healthcare spending in the form of pent-up demand. ${ }^{1}$ Counter-arguments defending the ACA state that the law exposes the limitations to such autonomy over the medical profession, as the U.S. healthcare system is ridden with excess, waste, and social injustice. Additional examples of these limitations are as follows: 1) the majority of our healthcare system is currently paid based on its volume versus its provided value; 2 ) the U.S. experiences poorer health outcomes than other developed nations despite the fact that the U.S. spends the more on its healthcare than any other developed nation; and 3) there is a lack of full stakeholder engagement to provide better coordinated and informed care to patient populations.

Public health policy seeks to balance the scales between government and private market interests. The ACA is a timely example of added weight to the scale of public health governance to counter-balance the weight of the private healthcare market. Competing interests between these two forces date back to the beginning of the twentieth century, with the ACA's weight resembling that of the Social Security Amendments of 1965, our government's second most recent quantum leap toward equitable healthcare for those of low socioeconomic status. The discussion below outlines the types of policies and laws governing healthcare, unique healthcare issues faced by particularly vulnerable populations, and future challenges and opportunities under the ACA. Lastly, the article provides brief recommendations on best practices to address future challenges presented by the ACA. 


\section{Policies and Laws Governing Healthcare}

The philosophical sub-discipline of bioethics plays a major role in healthcare legislation. Thus, there are two traditional types of policies and laws governing healthcare: 1) those defining the function and power of public health agencies, and 2) those directly serving to protect and promote public health. Together, these two types of policies and laws promulgate both the power and intentions of the government to preserve the health of the population. ${ }^{1}$

The executive branch of the federal government implements and enforces laws and appoints heads of federal government agencies. The U.S. Department of Health and Human Services (HHS) is the cabinet-level department of the U.S. government that oversees and addresses human health issues and defines the function and power of its several operating divisions and agencies. Some HHS agencies include the Centers for Medicare and Medicaid Services (CMS) and the Substance Abuse and Mental Health Services Administration. The HHS is tasked with oversight of the ACA; however, the Internal Revenue Service is responsible for overseeing the tax provisions within the ACA.

Governments have the ability to incentivize and promote healthy consumer behavior not only via legislation at the federal and state level, such as through the ACA, but also at the city level. For example, in order to address the current obesity epidemic, the city of Berkeley, California, implemented a Pigovian tax that is charged to distributors of certain sugar-sweetened beverages such as sweetened teas and soda (also called "Measure D"). This city ordinance caused for a tax levy of "one cent (\$0.01) per fluid ounce on the privilege of distributing sugar-sweetened beverage products in the city."3 Although unsuccessful, the American Beverage Association, a private market interest, spent millions of dollars publicly opposing Measure D. ${ }^{4}$ In essence, Measure D serves to balance its governmental scale against private market interests in order to protect the public health of the city of Berkeley, California.

\section{Unique Healthcare Issues of Vulnerable Populations}

Financially vulnerable populations encompass those living at or slightly above the federal poverty level, while clinically vulnerable populations include those with high-risk, chronic conditions (such as cancer). These two populations exist both separately and combined, and equally struggle to afford ever-increasing and expensive out-of-pocket expenses in the form of insurance premiums, co-insurance, co-payments, and deductibles. Prior to the ACA, insurance payers were allowed to deny insurance coverage to patients with pre-existing conditions, thereby exacerbating the socioeconomic issue of unaffordable coverage and compromised health in low income populations with high-risk, chronic conditions. ${ }^{5}$

Clinically vulnerable populations also include those with mental/behavioral health issues such as substance abuse disorders. Substance abuse occurs in various forms; alcoholism and non-medical use of prescription medications such as opiates, sedatives, pain-killers, and tranquilizers fall under the category of substance abuse. Patients with mental health and substance abuse issues, along with other medical conditions such as cancer, encompass two-thirds of high-use, high-cost patient spending in the healthcare system. ${ }^{6}$ Current studies also demonstrate a positive correlation between socioeconomic status, and substance abuse and mental disorders. ${ }^{7,8,9}$

The forms of laws and regulations described above seek to protect and/or improve the health of vulnerable populations, and balance the scales between bioethics and business. The ACA is coined as a pivotal moment in our healthcare system's history that, among several of its provisions and programs, increased access to care for millions of individuals. Examples include, but are not limited to, expanded Medicaid coverage to individuals living at or below $138 \%$ of the poverty level, government subsidized commercial health coverage for qualifying individuals living above $138 \%$ but below $400 \%$ of the federal poverty level, and access to care for high-risk cancer patient populations that were previously denied insurance coverage for their pre-existing condition. ${ }^{1}$ Further, the ACA requires that health insurance sold to newly eligible adults on Health Insurance Exchanges or provided under Medicaid include coverage for substance abuse treatment. ${ }^{10}$ Table 1 provides a general overview of the ACA's key provisions, and includes brief descriptions of how those features affect individuals and families, health care providers, insurers, employers, and taxpayers. ${ }^{15}$

(C) The Internet Journal of Allied Health Sciences and Practice, 2016 
Table 1. Key Features of the ACA Titles I-X

\begin{tabular}{|c|c|}
\hline ACA TITLE & Key Features \\
\hline $\begin{array}{l}\text { TITLE I- Quality, affordable } \\
\text { health care for all } \\
\text { Americans }\end{array}$ & 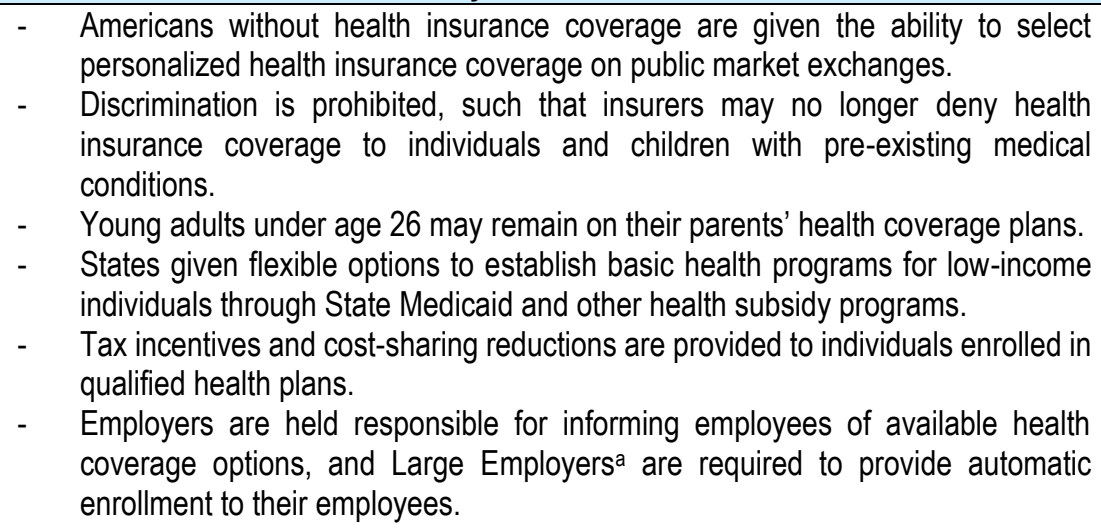 \\
\hline $\begin{array}{l}\text { TITLE II- Role of public } \\
\text { programs }\end{array}$ & $\begin{array}{l}\text { - Expanded Medicaid coverage to individuals and families living at or below } 138 \\
\text { - } \\
\text { - Simplified Medicaid and Children's Health Insurance Program (CHIP) enrollment } \\
\text { procedures. } \\
\text { Improved quality of Medicaid services, which includes support for both pregnant } \\
\text { and parenting teens and women, expanded Medicaid reimbursement, and } \\
\text { rebates for prescription drugs. } \\
\text { - The development and inclusion of a core, recommended set of adult health quality } \\
\text { measures under the Medicaid Quality Measurement Program; measures shall be } \\
\text { reported to the CMS in a standardized format and on behalf of Medicaid } \\
\text { beneficiaries. }\end{array}$ \\
\hline $\begin{array}{l}\text { TITLE III- Improving the } \\
\text { quality and efficiency of } \\
\text { health care }\end{array}$ & $\begin{array}{l}\text { Medicare payments are linked to quality outcomes, versus patient volume, } \\
\text { through the development and use of quality reporting and physician feedback } \\
\text { programs and value-based modifiers under the physician fee schedule, and by } \\
\text { virtue of national strategy to improve health care quality. } \\
\text { The development of innovative patient care models, such as the Medicare Shared } \\
\text { Savings Program and payment bundling for clinical episodes. } \\
\text { Ensured beneficiary access to clinical care and services, including mental health } \\
\text { and ambulatory services, and integration of quality improvement and patient } \\
\text { safety training and education programs for health professionals. } \\
\text { Improved payment accuracy and payment adjustments for specified services and } \\
\text { products, including home health care and biosimilar products, and payment } \\
\text { protections for rural health care providers. }\end{array}$ \\
\hline $\begin{array}{l}\text { TITLE IV- Prevention of } \\
\text { chronic disease and } \\
\text { improving public health }\end{array}$ & $\begin{array}{l}\text { Funding commitments to programs that promote illness prevention, wellness, and } \\
\text { contribute to the public health. } \\
\text { Increased and improved access to preventative health services for Medicare and } \\
\text { Medicaid beneficiaries. }\end{array}$ \\
\hline $\begin{array}{l}\text { TITLE V- Health care } \\
\text { workforce }\end{array}$ & $\begin{array}{l}\text { - Funding for employment incentives, such as scholarships and loan repayment } \\
\text { programs, to increase the number of primary care physicians, nurses, physician } \\
\text { assistants, mental health providers, and dental health providers in medically } \\
\text { underserved areas. }\end{array}$ \\
\hline
\end{tabular}

Note: a "Large Employer" as defined under Section 1304 of the ACA; "in connection with a group health plan with respect to a calendar year and a plan year, an employer who employed an average of at least 101 employees on business days during the preceding calendar year and who employs at least 1 employee on the first day of the plan year." 
Table 1. Key Features of the ACA Titles I-X (cont.)

\begin{tabular}{|c|c|}
\hline ACA TITLE & Key Features \\
\hline $\begin{array}{l}\text { TITLE VI- Transparency } \\
\text { and program integrity }\end{array}$ & 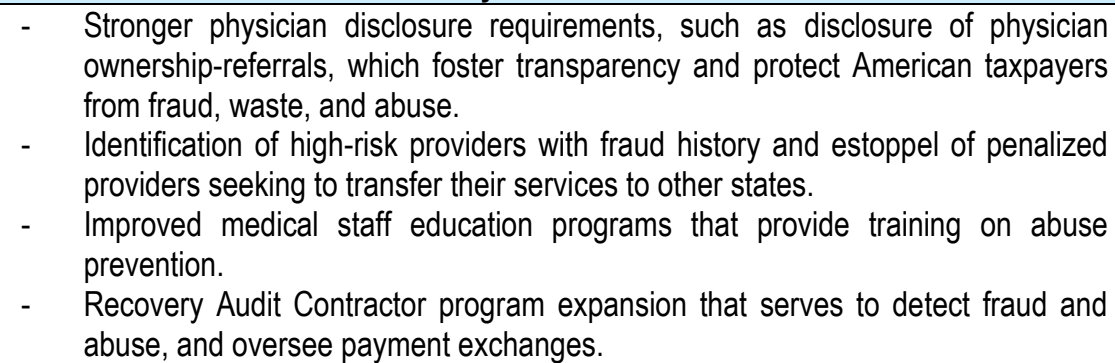 \\
\hline $\begin{array}{l}\text { TITLE VII- Improving } \\
\text { access to innovative } \\
\text { medical therapies }\end{array}$ & $\begin{array}{l}\text { - } \quad \text { Support for innovative, medically therapeutic programs that create monetary } \\
\text { savings across health systems and communities. } \\
\text { - } \quad \text { Extended discounts for prescription drugs and biologicals administered by health } \\
\text { care providers to adults and children in low income communities. }\end{array}$ \\
\hline $\begin{array}{l}\text { TITLE VIII- Community } \\
\text { Living Assistance Services } \\
\text { and Supports Act (CLASS } \\
\text { Act) }\end{array}$ & $\begin{array}{l}\text { - A national, voluntary, and self-funded insurance program (tax-payer free) that pays } \\
\text { for community assistance living services for disabled individuals. } \\
\text { - Benefits may be used to support diverse forms of community support services, } \\
\text { such as home health care that allows disabled individuals to continue to work near } \\
\text { and live in their homes. }\end{array}$ \\
\hline $\begin{array}{l}\text { TITLE IX- Revenue } \\
\text { provisions }\end{array}$ & $\begin{array}{l}\text { - The ACA is intended to reduce the federal deficit and reduce tax-payer burden by } \\
\text { more than one hundred billion dollars by the year } 2020 \text {. } \\
\text { - Tax credits are intended to reduce health insurance premiums and financially } \\
\text { assist individuals and families with health insurance costs. } \\
\text { - Revenue offset provisions seek to oversee and monitor improper health care } \\
\text { spending, such as excessive remuneration paid by certain health insurers, and } \\
\text { impose excise tax on considerably expensive employer-sponsored health } \\
\text { coverage. }\end{array}$ \\
\hline $\begin{array}{l}\text { TITLE X- Strengthening } \\
\text { quality, affordable health } \\
\text { care for all Americans }\end{array}$ & $\begin{array}{l}\text { - } \quad \text { Reauthorization of the Indian Health Care Improvement Act; provides Native } \\
\text { Americans with access to health care services. } \\
\text { - } \quad \text { Modernization of the Native American health care system with the goal to improve } \\
\text { health care for } 1.9 \text { million Native Americans. }\end{array}$ \\
\hline
\end{tabular}

The ACA- Looking Ahead

The ACA afforded health insurance coverage to individuals who were either underinsured or uninsured prior to the ACA's enactment. The purpose of the ACA is to increase the value of American healthcare and improve the overall health status of individuals through the encouragement of population-based payments for rendered medical services, preventative and evidencebased medicine, and coordinated care. In essence, the ACA is a governmental measure and tool that is and can be used as a conduit to attain and achieve health equity across income levels. Policies and programs implemented by virtue of the ACA have great potential to decrease America's "paradox of excess and deprivation" and address socioeconomic stereotypes and barriers in healthcare. ${ }^{8}$

The ACA however, and as many know, is neither exempt from nor without limitations and critique. U.S. healthcare spending is expected to increase as a result of 1) increased insurance plan enrollment through Health Insurance Exchanges and Medicaid expansion, 2) a larger aging population, and 3) an improved economy. This increase in healthcare utilization has and will lead to a "pent-up demand" for healthcare services in the marketplace, and increases in cost and payment for rendered medical services. ${ }^{1,11}$ Many also accuse programs implemented by virtue of the ACA of interfering with and reducing the potential to introduce stronger private market force and competition into the healthcare marketplace, and further accuse the ACA of merely strengthening the market force of larger, wealthier, and better established health systems that have resources in place to implement complicated value-based payment structures. ${ }^{12}$

\section{Summary}

Now that we have briefly explored and defined some of the types of policies and laws governing healthcare, financially and clinically vulnerable populations, and future challenges and opportunities under the ACA, we may now summarize upon the notion and need to balance the scales between bioethics and the marketplace. Inaction on current issues of excess and waste in our healthcare system/marketplace and income inequality results in matters of life or death for millions, especially financially 
and/or clinically vulnerable populations that are less fortunate to achieve levels of wealth that would allow them the opportunity to pay for expensive, yet medically necessary, medical procedures. As the U.S. market and economy improves, and as costs of living rise as a result, it is important to identify and implement innovative ways to balance the scales between the two forces so as to eliminate waste, reduce spending long-term for medially-necessary procedures, enhance patient education and access to care, obtain social justice, and produce healthier patient populations.

\section{Recommendations and Key Takeaways}

Although marketplace concerns about the ACA are well warranted, it is important to understand the overarching need to reduce waste and enhance quality and value, especially in healthcare. Costs are and can be astronomically high relative to individual income, and families, employers, and communities alike are sorely impacted by poor public health outcomes that could be prevented according to evidence-based medicine. Economic analysis projects a decrease in healthcare spending over time, particularly after year 2023, as a result of measures put in place by ACA provisions, which include shifting healthcare payment structures from fee-for-service payments that are volume-based to population-based payments that are value-based. ${ }^{1}$ Valuebased payments, also termed alternative payment models (APMs), distribute provider payments in accordance to value provided to patient populations, versus the number of times the providers provide a tangible service. A significant number of APMs have been developed and disseminated across a wide range of health networks and authorities, clinical specialties, and health systems.

A key and laudable feature of APMs is that they promote high quality care at relatively lower costs for health consumers, and in financially feasible ways for providers. The American Medical Association and Center for Healthcare Quality and Payment Reform jointly outline three particular characteristics of successful, physician-focused APMs in their recently released Executive Summary of APMs: 1) APM design must be flexible and must give providers the ability to deliver the most effective and efficient patient care possible; 2) APMs must provide financial and tangible resources that allow its providers to deliver the highest quality care possible, and distribute adequate, predictable, risk-adjusted payments that are tailored to the unique characteristics of its providers' patient populations; and 3) APM design must ensure, to patients and payers, that care costs will be either controlled or reduced so as to not sacrifice quality for the sake of lower costs, and only hold providers accountable for care quality and costs that are exclusively under the providers' control. The Medicare Access and CHIP Reauthorization Act of 2015 (MACRA) was created and implemented by virtue of the ACA, and strongly encourages the use of such APMs. ${ }^{16,17}$

Examples of APMs include, but are not limited to, bundled or clinical episode payments and condition-based payments for physician services. Bundled payments can be disease- or condition-specific, and may account for multi-specialty care delivered to unique sets of patients undergoing specific courses of care. Condition-based payments for physician services are valuable in that physicians have the flexibility to use effective and efficient treatment options, regardless of cost, if utilization of lower cost options compromise patient care. The Clinical Episode Payment Work Group, as part of the Health Care Payment Learning and Action Network (HCP LAN), published a white paper summarizing its formularies of and recommendations for condition-specific clinical episode payments for elective joint replacement, maternity care, and coronary artery disease. ${ }^{18}$ Additional APMs endorsed by both the CMS and Agency for Healthcare Research and Quality include Accountable Care Organizations (ACOs) and Patient Centered Medical Homes (PCMHs). ${ }^{19,20}$

Given that value-based payment structures, or APMs, are a relatively new concept in U.S. healthcare, it is recommended that stakeholders and stakeholder organizations collaborate and exchange ideas with one another in order to identify quality measures and quality measurement tools and approaches. Programs such as the HCP LAN and Healthy People 2020, for example, have been introduced by the CMS and the Office of Disease Prevention and Health Promotion, respectively, to facilitate collaboration among communities and business sectors to exchange such ideas. ${ }^{13,14}$ These programs encourage shared decision making and stakeholder engagement that must undeniably take place in order to balance the scales between the marketplace and public health equity.

\section{References}

1. Teitelbaum, J. B., \& Wilensky, S. E. (2016). Essentials of health policy and law. Jones \& Bartlett Publishers.

2. U.S. Department of Health and Human Services (2015, October 27). HHS Agencies \& Offices. Retrieved from http://www.hhs.gov/about/agencies/hhs-agencies-and-offices/index.html

3. Natl. Fedn. of Indep. Bus. v. Sebelius (Secretary of Health and Human Services), 567 U.S. 11 (2012)

4. City of Berkeley (2014). Ordinance no. \#, \#\# - N.S. Imposing a General Tax on the Distribution of Sugar-Sweetened Beverage Products. Retrieved from https://www.cityofberkeley.info/uploadedFiles/Clerk/Elections/Sugar\%20Sweeetened\%20Beverage $\% 20 T a x \% 20 \% 20$ \%20Full\%20Text.pdf

(c) The Internet Journal of Allied Health Sciences and Practice, 2016 
5. Dinkelspiel, F. (2015, February 5). Around $\$ 3.4 \mathrm{M}$ spent on Berkeley soda tax campaign. Retrieved from http://www.berkeleyside.com/2015/02/05/around-3-4m-spent-on-berkeley-soda-tax-campaign/

6. Du, X. L., Lin, C. C., Johnson, N. J., \& Altekruse, S. (2011). Effects of individual-level socioeconomic factors on racial disparities in cancer treatment and survival. Cancer, 117(14), 3242-3251.

7. Melek, S. P., Norris, D. T., \& Jordan Paulus, F. S. A. (2014). Economic impact of integrated medical-behavioral healthcare. Milliman American Psychiatric Association Report.

8. Stewart, T. D., \& Reed, M. B. (2015). Lifetime nonmedical use of prescription medications and socioeconomic status among young adults in the United States. The American journal of drug and alcohol abuse, 41(5), 458-464.

9. Bodenheimer, T. S., \& Grumbach, K. (2016). Understanding Health Policy: A Clinical Approach, 7th Edition. New York, NY: McGraw-Hill Companies, Inc.

10. Stansfeld, S. A., Clark, C., Rodgers, B., Caldwell, T., \& Power, C. (2011). Repeated exposure to socioeconomic disadvantage and health selection as life course pathways to mid-life depressive and anxiety disorders. Social psychiatry and psychiatric epidemiology, 46(7), 549-558.

11. Office of the National Drug Control Policy (n.d.). Substance Abuse and the Affordable Care Act. Retrieved from https://www.whitehouse.gov/ondcp/healthcare

12. Fertig, A, Carlin, C., \& Long, S. (2015). Panel Paper: Pent-up Health Care Demand after the Affordable Care Act (ACA). Retrieved from https://appam.confex.com/appam/2015/webprogram/Paper13025.html

13. Obenhaus, M. (2016). The Next Frontier in Healthcare Reform and Why it Will Harm Consumers (Web log post). Retrieved from https://gymnasiumsite.wordpress.com/2016/03/09/the-next-frontier-in-healthcare-reform-and-why-it-will-harmconsumers/

14. Centers for Medicare and Medicaid Services (2016, March 3). Health Care Payment Learning and Action Network. Retrieved from https://innovation.cms.gov/initiatives/Health-Care-Payment-Learning-and-Action-Network/

15. Office of Disease Prevention and Health Promotion (2016, April 8). About Healthy People. Retrieved from https://www.healthypeople.gov/2020/About-Healthy-People

16. U.S. Department of Health \& Human Services (2015, August 28). The Affordable Care Act, Section by Section. Retrieved from http://www.hhs.gov/healthcare/about-the-law/read-the-law/index.html

17. Miller, H. D. \& Marks, S. S. (n.d.). A Guide to Physician-Focused Alternative Payment Models. Retrieved from http://www.chqpr.org/downloads/Physician-FocusedAlternativePaymentModels.pdf

18. Centers for Medicare and Medicaid. (n.d.). Quality Payment Program: Delivery System Reform, Medicare Payment Reform, \& MACRA. Retrieved from https://www.cms.gov/Medicare/Quality-Initiatives-Patient-Assessment-Instruments/Value-BasedPrograms/MACRA-MIPS-and-APMs/MACRA-MIPS-and-APMs.html

19. Health Care Payment Learning and Action Network. (2016). Accelerating and aligning clinical episode payment models. Retrieved from http://hcp-lan.org/workproducts/cep-whitepaper-final.pdf

20. Centers for Medicare and Medicaid. (2015, January 6). Accountable Care Organizations (ACO). Retrieved from https://www.cms.gov/Medicare/Medicare-Fee-for-Service-Payment/ACO/index.html?redirect=/aco

21. A Agency for Healthcare Research and Quality. (n.d.). Defining the PCMH. Retrieved from https://pcmh.ahrq.gov/page/defining-pcmh 